\title{
Outcomes of robotic esophagectomy
}

\author{
Amy Young ${ }^{1 \#}$, José María Alvarez Gallesio ${ }^{2 \#}$, David B. Sewell ${ }^{3}$, Rebecca Carr ${ }^{3}$, Daniela Molena ${ }^{3}$ \\ ${ }^{1}$ Department of Surgery, Philadelphia College of Osteopathic Medicine, Philadelphia, PA, USA; ${ }^{2}$ Department of Surgery, Division of Cardiothoracic \\ Surgery, Hospital Alemán of Buenos Aires, Buenos Aires, Argentina; ${ }^{3}$ Thoracic Service, Department of Surgery, Memorial Sloan Kettering Cancer \\ Center, New York, NY, USA \\ Contributions: (I) Conception and design: D Molena; (II) Administrative support: None; (III) Provision of study materials or patients: None; (IV) \\ Collection and assembly of data: None; (V) Data analysis and interpretation: None; (VI) Manuscript writing: All authors; (VII) Final approval of \\ manuscript: All authors. \\ "These authors contributed equally to this work as first authors. \\ Correspondence to: Daniela Molena, MD. Associate Attending, Director of Esophageal Surgery, Thoracic Service, Department of Surgery, Memorial \\ Sloan Kettering Cancer Center, 1275 York Avenue, New York, NY 10065, USA. Email: molenad@mskcc.org.
}

\begin{abstract}
Esophagectomy has long been considered the standard of care for early-stage $(\leq \mathrm{T} 2 \mathrm{~N} 0)$ esophageal cancer. Minimally invasive esophagectomy (MIE), using a combined laparoscopic and thoracoscopic approach, was first performed in the 1990s and showed significant improvements over open approaches. Refinement of MIE arrived in the form of robotic-assisted minimally invasive esophagectomy (RAMIE) in 2004. MIE is a challenging procedure for which consensus on optimal technique is still elusive. Although nonrobotic MIE confers significant advantages over open approaches, MIE remains associated with stubbornly high rates of complications, including pneumonia, aspiration, arrhythmia, anastomotic leakage, surgical site infection, and vocal cord palsy. RAMIE was envisioned to improve operative-associated morbidity while achieving equivalent or superior oncologic outcomes to nonrobotic MIE. However, owing to RAMIE's significant upfront costs, steep learning curve, and other requirements, adoption remains less than widespread and convincing evidence supporting its use from well-designed studies is lacking. In this review, we compare operative, oncologic, and quality-of-life outcomes between open esophagectomy, nonrobotic MIE, and RAMIE. Although RAMIE remains a relatively new and underexplored modality, several studies in the literature show that it is feasible and results in similar outcomes to other MIE approaches. Moreover, RAMIE has been associated with favorable patient satisfaction and quality of life.
\end{abstract}

Keywords: Esophageal cancer; esophagectomy; open thoracotomy; minimally invasive esophagectomy (MIE); robotic-assisted esophagectomy

Submitted May 05, 2020. Accepted for publication Aug 05, 2020.

doi: $10.21037 /$ jtd-2019-rts-07

View this article at: http://dx.doi.org/10.21037/jtd-2019-rts-07

\section{Introduction}

Esophageal cancer is the eighth most common malignancy worldwide, with an annual incidence of 572,034 cases, according to the GLOBOCAN database (1). The role of esophagectomy in early-stage $(\leq \mathrm{T} 2 \mathrm{~N} 0)$ esophageal cancer is well established, and the procedure is considered the cornerstone of curative treatment for patients with this disease (2).

Although surgery in general has undergone an evolution toward minimally invasive techniques during the last several decades, the safety of minimally invasive esophagectomy (MIE) and its routine use have taken longer to establish. However, several recent randomized controlled trials have shown that MIE results in lower morbidity and better shortterm quality of life, compared with open esophagectomy $(3,4)$.

Esophagectomy is a complex procedure, and controversy remains regarding the optimal technique for this operation. A thoracic approach is mandatory for optimal resection 


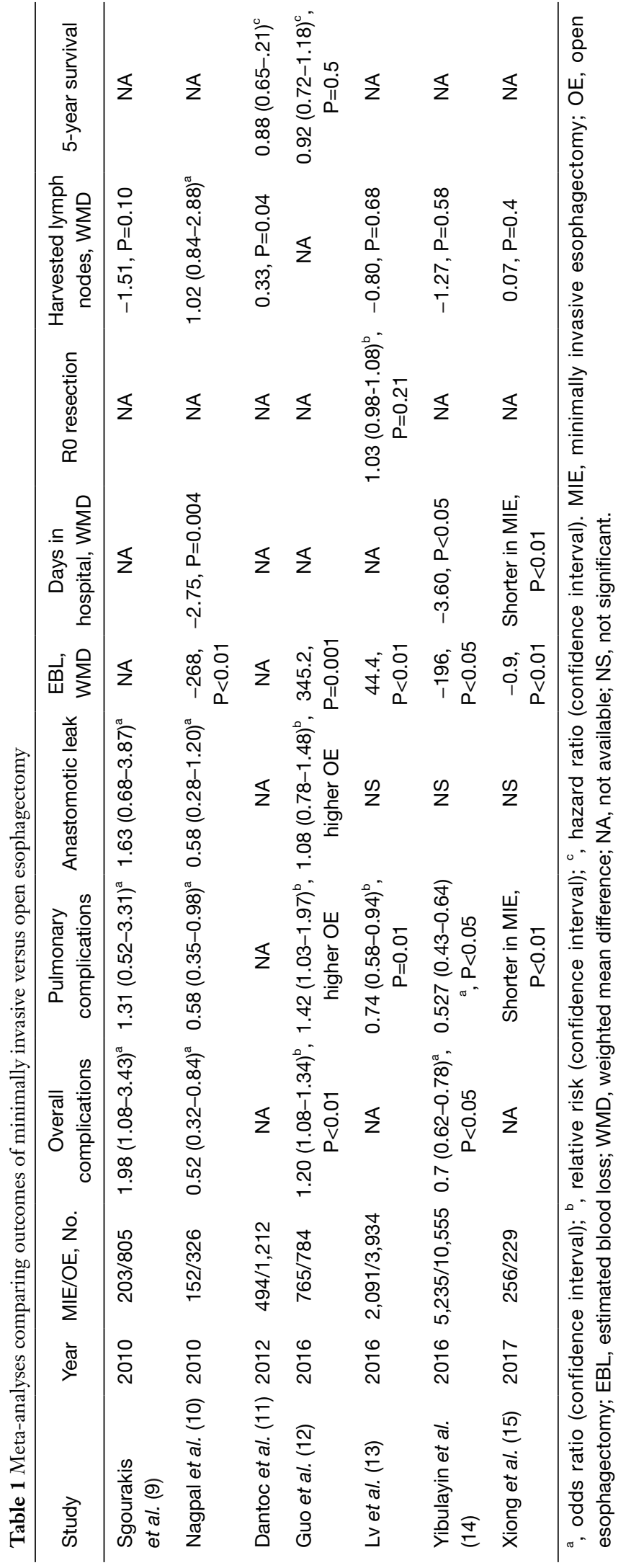

of the tumor and surrounding lymph nodes (5). However, even with refinement of the approach, and even when it is performed by surgeons with considerable expertise with the technique, high complication rates persist for esophagectomy. In the Western world, surgical morbidity has been reported to be as high as $23 \%$ to $50 \%$, with surgical mortality of $2 \%$ to $8 \%(6)$. Hence, there is a constant drive among surgeons to identify innovations and refinements that can improve outcomes for these patients.

To minimize the morbidity associated with open esophagectomy, MIE was developed in the 1990s. The current definition of MIE includes the use of a laparoscopic and/or thoracoscopic approach (6), and more recently robotic assistance has been included. Robotic esophagectomy was first described by Kernstine and colleagues in 2004 (7). Over the past 15 years, roboticassisted minimally invasive esophagectomy (RAMIE) has begun to grow in popularity, as the use of the DaVinci system has become more widespread and training programs have adopted this technique. Robotic surgery offers the advantages of enhanced visualization and freedom of motion. Whereas robotic approaches are routinely used for a range of oncologic procedures, including radical prostatectomy and hysterectomy, the technique is still being investigated for esophagectomy.

Candidates for MIE are also candidates for RAMIE. The indications for MIE include Barrett's esophagus with highgrade dysplasia, end-stage achalasia, esophageal strictures, and esophageal cancer (8). The specific steps and details of the procedure are beyond the scope of this article. In this chapter, we will compare operative, oncologic, and qualityof-life outcomes between RAMIE, nonrobotic MIE, and open esophagectomy.

\section{Operative outcomes}

The benefits of MIE over open surgery have been established in several retrospective studies and were summarized in a recently published meta-analysis (9-15) (Table 1). These studies reported that perioperative total complications and intraoperative estimated blood loss (EBL) were lower for MIE than for open esophagectomy. Overall, the most common postoperative complications following MIE are respiratory complications (pneumonia, aspiration), followed by arrhythmia, anastomotic leakage, surgical site infection, and vocal cord palsy. These complications have varying effects on outcomes, and early accurate diagnosis is required to avoid life-threatening issues. Although it is not 
yet the state of the practice, it is hoped that, in the future, such complications could be largely avoided through the optimization of the surgical techniques used for MIE.

To prevent pneumonia in esophagectomy patients, adequate breathing, early mobilization, and effective postoperative pain management are key. Accordingly, MIE, which achieves improvements in breathing, mobilization, and pain over open esophagectomy, has been shown to reduce the incidence of pulmonary infection during the postoperative course $(3,8,12-15)$. Biere et al. reported the results of a randomized controlled trial comparing outcomes between MIE and open esophagectomy (3). They found that only $9 \%$ of MIE patients developed pulmonary infection within the first 2 postoperative weeks, compared with $29 \%$ of open esophagectomy patients $(P=0.005)$. Moreover, mirroring the findings from the meta-analysis, they observed significantly less vocal-cord paralysis ( $2 \% v s$. $14 \% ; \mathrm{P}=0.01$ ) and $\mathrm{EBL}$ \{median [range], 200 [20-1,200] vs. $475[50-3,000] \mathrm{mL} ; \mathrm{P}<0.001\}$ in patients undergoing MIE versus open esophagectomy.

The reduced morbidity associated with minimally invasive techniques results in a decrease in hospital and ICU stay, compared with open approaches (19.6 and 7.6 days vs. 14.9 and 4.5 days) (16). The results of the ECOG 2202 triala multicenter phase II prospective trial designed to evaluate the feasibility of MIE for patients with high-grade dysplasia or esophageal cancer-observed 30-day mortality of $2.1 \%$ in patients who underwent MIE. ICU stay was 2 days for MIE patients, with an overall hospital stay of 9 days (17).

Although thoracoscopic MIE has been shown to be superior to open esophagectomy in operative outcomes, some limitations have been noted-for instance, the twodimensional visualization of the MIE approach and the limited freedom of instrumental movements due to the positioning of the fulcrum at the intercostal space. RAMIE was developed to address some of these limitations. The robotic platform provides three-dimensional vision of the surgical field and 10-fold magnification and includes an EndoWrist instrument with 7 degrees of freedom, which can translate the surgeon's natural movements. Of importance, Gergadus reported that patients who underwent RAMIE experienced less pain than patients who underwent other MIE techniques. The authors suggested this finding was attributable to the longer instruments of the robotic platform, which carry the advantage of placing the fulcrum inside the thoracic cavity instead of at the intercostal space (18).

In addition, RAMIE has been noted to include other potential intraoperative and postoperative advantages. The robot is especially useful in operating fields where locations are hard to reach. Bodner et al. suggested that the esophagus is an ideal organ for the use of RAMIE, as the operative area is relatively small and difficult to maneuver around. Hence, RAMIE allows a meticulous dissection, with the magnified field enhancing the ability to operate on moving structures caused by breathing and pulsatile movements of the heart and the aorta (19).

Another benefit of the RAMIE technique is the decreased volume of EBL, which is secondary to the detailed and magnified dissection capabilities of the robotic platform. In a retrospective study by Cerfolio et al., no patients who underwent RAMIE required blood transfusion (20). A metaanalysis by Jin et al. confirmed that RAMIE definitively reduced EBL, compared with other MIE approaches [mean difference (MD), $-33.2268 ; \mathrm{P}=0.0075]$. Perioperative complication rates were similar between RAMIE and other MIE approaches, with no statistically significant differences in the incidence of anastomotic leak, pneumonia, arrhythmia, or chylothorax. In its favor, RAMIE did result in fewer cases of vocal cord palsy [odds ratio (OR), 0.5696; $\mathrm{P}=0.0447]$ (21). This severe complication is secondary to intraoperative recurrent laryngeal nerve injury. Although, at present, there are too few analyses of RAMIE versus MIE to make definitive conclusions, the better visualization afforded by the robotic platform during lymph node dissection gives hope that wider use of RAMIE will eventually lead to lower rates of vocal cord paralysis and aspiration.

Postoperative mortality and length of hospital stay were also found to be similar between RAMIE and MIE. In a metaanalysis, 30-day mortality (OR, 0.8341; $\mathrm{P}=0.7696$ ), 90-day mortality (OR, 0.3224; $\mathrm{P}=0.3329)$, in-hospital mortality (OR, 0.3733; $\mathrm{P}=0.3895$ ), and length of hospital stay (MD, -5.0228 days; $\mathrm{P}=0.1342$ ) did not differ between techniques (21).

A common perceived shortcoming of any MIE technique, especially RAMIE, is that it requires increased intraoperative time. However, Jin et al. described no significant difference in operation time between conventional approaches and MIE (MD, $24.3655 \mathrm{~min}$; $\mathrm{P}=0.2402$ ) (21). Furthermore, Weksler et al. observed homologous operative time between RAMIE and any other MIE [449 min (RAMIE) vs. $510 \mathrm{~min}$; $=0.07$ ], including the time required to dock and prepare the robot (22).

In conclusion, MIE results in better operative outcomes than open esophagectomy. RAMIE results in lower incidence of EBL, pain, and vocal-cord paralysis than nonrobotic MIE. The adoption of RAMIE does include 
increased costs, a complex learning curve, and specific requirements for room layout and robot docking. For these reasons, many remain skeptical that RAMIE is superior to MIE.

\section{Oncologic outcomes}

Overall and disease-free survival have been shown to be similar between MIE and open esophagectomy (3). Straatman et al. observed similar overall 3-year survival between MIE and open esophagectomy among patients with esophageal cancer of any stage [41.2\% (MIE) vs. $42.9 \%$ (open); $\mathrm{P}=0.633]$. Furthermore, in this study, diseasefree survival was not significantly different between MIE and open esophagectomy (37.3\% vs. $42.9 \% ; \mathrm{P}=0.602)$ (8). In addition, in a recent national population study, matched overall survival was not significantly different between MIE or RAMIE versus open esophagectomy $(\mathrm{P}=0.306)$ (23).

Lymph node harvest plays a crucial role in staging and stratification of esophageal cancer. Patients with esophageal cancer have a high rate of cancer metastasis, especially on the recurrent laryngeal nerve area in cases of squamous cell histologic type. Extended lymphadenectomy is associated with improved overall survival (24). Rizk et al. demonstrated that staging was most accurate when at least 18 lymph nodes were harvested between the thoracic and abdominal areas during esophagectomy (25). The National Comprehensive Cancer Network (NCCN) guidelines recommend harvesting at least 15 nodes (26). Therefore, because of the staging and prognostic importance of adequate lymphadenectomy, it is critical that the surgical approach used for esophagectomy allows optimal lymph node exposure and dissection. Patients undergoing nonrobotic MIE or RAMIE had more lymph nodes harvested than patients undergoing open surgery $(23,27)$. Experience suggests that surgeons find it easier to reach the upper mediastinal nodes and achieve complete oncological resection during MIE—and, in particular, RAMIE—-than by conventional thoracotomy. Van Der Horst et al. reported an average lymph node yield of 24 using RAMIE, which is well above the NCCN recommendation (28). In a pooled data analysis from a meta-analysis, the number of lymph nodes harvested did not differ significantly between MIE and RAMIE (MD, 0.82; $\mathrm{P}=0.20$ ) (21).

The ability to obtain a complete microscopic R0 resection is another important predictor of long-term survival in patients with esophageal cancer (29). In a 2 -year single-center study, Cerfolio et al. reported that
$\mathrm{R} 0$ resection was achieved in all patients who underwent RAMIE (20). The authors suggested that the robotic approach was a defining factor in attaining R0 resection, as it allowed better visualization and mobility during surgery. However, in a meta-analysis from Jin et al., the R0 resection rate was not statistically different between RAMIE and nonrobotic MIE (OR, 1.11; $\mathrm{P}=0.8647)$ (21).

\section{Quality-of-life measures}

An important consideration for the validation of a new technique is its impact on quality of life. Luketich et al. showed that, following MIE, patients return to their baseline quality-of-life scores and that such scores were similar to those for the mean overall population (29). Following open surgery, patients often report protracted pain in the thoracotomy scar and dysfunction in the right shoulder. Postoperative thoracotomy syndrome, which has been reported to occur in up to one-third of patients, has a negative influence on performance of daily activities (30).

In a study from Parameswaran et al., fatigue scores were similar between open esophagectomy and MIE at 3 months but were better at 6 months among patients who had undergone MIE. Similarly, ability to perform daily living activities was similar between the two groups immediately after surgery but was better at 3 months in the MIE group (31). Furthermore, in a recently published randomized controlled study, RAMIE was associated with better short-term quality of life and short-term postoperative functional recovery, compared with open esophagectomy (4).

Sugawara et al. investigated quality of life between nonrobotic MIE and RAMIE. They reported that, at 24 months after surgery, global quality of life $(\mathrm{P}=0.01)$ and emotional function $(\mathrm{P}=0.01)$ were significantly higher in the RAMIE group than in the nonrobotic MIE group. Moreover, they observed less fatigue $(\mathrm{P}=0.04)$, pain $(\mathrm{P}=0.04)$, and insomnia $(\mathrm{P}=0.04)$ in patients who had undergone RAMIE (32).

A Japanese study examining patients who had undergone transmediastinal esophagectomy found that global health stats, physical functional scale scores, and cognitive functional scale scores were significantly higher in patients who had undergone robotic procedures, compared with those who had undergone laparoscopic transthoracic esophagectomy. In addition to the above quality-oflife measures, the authors investigated several subjective endpoints that correlate with patient wellness. They found that fatigue $(\mathrm{P}=0.003)$, nausea $(\mathrm{P}=0.032)$, pain $(\mathrm{P}=0.025)$, 
appetite loss $(\mathrm{P}=0.018)$, reflux $(\mathrm{P}=0.001)$, and taste score $(\mathrm{P}=0.041)$ were all significantly better after RAMIE than laparoscopic transthoracic esophagectomy (33). Hence, MIE_-and, in particular, RAMIE-results in superior quality of life outcomes.

\section{Conclusions}

Although RAMIE remains a relatively new and underexplored modality, several studies have demonstrated that the robotic approach is feasible and results in similar outcomes to other MIE approaches. Moreover, RAMIE has been associated with favorable results for patient satisfaction and quality of life, compared with other MIE techniques (30-33). However, RAMIE requires increased costs and a steep learning curve, and data from large randomized controlled trials investigating its use are currently lacking.

\section{Acknowledgments}

Funding: This study was supported, in part, by NIH/NCI Cancer Center Support Grant P30 CA008748.

\section{Footnote}

Provenance and Peer Review: This article was commissioned by the Guest Editor (Ghulam Abbas) for the series "Robotic Thoracic Surgery" published in Fournal of Thoracic Disease. The article has undergone external peer review.

Conflicts of Interest: All authors have completed the ICMJE uniform disclosure form (available at http://dx.doi. org/10.21037/jtd-2019-rts-07). The series "Robotic Thoracic Surgery" was commissioned by the editorial office without any funding or sponsorship. DM reports other from Intuitive, Boston Scientific, Johnson and Johnson, and Urogen, outside the submitted work. The authors have no other conflicts of interest to declare.

Ethical Statement: The authors are accountable for all aspects of the work in ensuring that questions related to the accuracy or integrity of any part of the work are appropriately investigated and resolved.

Open Access Statement: This is an Open Access article distributed in accordance with the Creative Commons Attribution-NonCommercial-NoDerivs 4.0 International License (CC BY-NC-ND 4.0), which permits the non- commercial replication and distribution of the article with the strict proviso that no changes or edits are made and the original work is properly cited (including links to both the formal publication through the relevant DOI and the license). See: https://creativecommons.org/licenses/by-nc-nd/4.0/.

\section{References}

1. Siegel RL, Miller KD, Jemal A. Cancer statistics, 2019. CA Cancer J Clin 2019;69:7-34.

2. Luketich JD, Alvelo-Rivera M, Buenaventura PO, et al. Minimally invasive esophagectomy: outcomes in 222 patients. Ann Surg 2003;238:486-94; discussion 494-5.

3. Biere SS, van Berge Henegouwen MI, Maas KW, et al. Minimally invasive versus open oesophagectomy for patients with oesophageal cancer: a multicentre, open-label, randomised controlled trial. Lancet 2012;379:1887-92.

4. van der Sluis PC, Van der Horst S, May AM, et al. Robot-assisted Minimally Invasive Thoracolaparoscopic Esophagectomy Versus Open Transthoracic Esophagectomy for Resectable Esophageal Cancer: A Randomized Controlled Trial. Ann Surg 2019;269:621-30.

5. Hulscher JBF, Van Sandick J, de Boer AGEM, et al. Extended transthoracic resection compared with limited transhiatal resection for adenocarcinoma of the esophagus. N Engl J Med 2002;347:1662-9.

6. Taurchini M, Cuttitta A. Minimally invasive and robotic esophagectomy: state of the art. J Vis Surg 2017;3:125.

7. Kernstine KH, DeArmond DT, Karimi M, et al. The robotic, 2-stage, 3-field esophagolymphadenectomy. J Thorac Cardiovasc Surg 2004;127:1847-9.

8. Straatman J, van der Wielen N, Cuesta MA, et al. Minimally Invasive Versus Open Esophageal Resection: Three-year Follow-up of the Previously Reported Randomized Controlled Trial: the TIME Trial. Ann Surg 2017;266:232-6.

9. Sgourakis G, Gockel I, Radtke A, et al. Minimally invasive versus open esophagectomy: meta-analysis of outcomes. Dig Dis Sci 2010;55:3031-40.

10. Nagpal K, Ahmed K, Vats A, et al. Is minimally invasive surgery beneficial in the management of esophageal cancer? A meta-analysis. Surg Endosc 2010;24:1621-9.

11. Dantoc M, Cox MR, Eslick GD. Evidence to support the use of minimally invasive esophagectomy for esophageal cancer: a meta-analysis. Arch Surg 2012;147:768-76.

12. Guo W, Ma X, Yang S, et al. Combined thoracoscopiclaparoscopic esophagectomy versus open esophagectomy: a meta-analysis of outcomes. Surg 
Endosc 2016;30:3873-81.

13. Lv L, Hu W, Ren Y, et al. Minimally invasive esophagectomy versus open esophagectomy for esophageal cancer: a meta-analysis. Onco Targets Ther 2016;9:6751-62.

14. Yibulayin W, Abulizi S, Lv H, et al. Minimally invasive oesophagectomy versus open esophagectomy for resectable esophageal cancer: a meta-analysis. World J Surg Oncol 2016;14:304.

15. Xiong WL, Li R, Lei HK, et al. Comparison of outcomes between minimally invasive oesophagectomy and open oesophagectomy for oesophageal cancer. ANZ J Surg 2017;87:165-70.

16. Verhage RJ, Hazebroek EJ, Boone J, et al. Minimally invasive surgery compared to open procedures in esophagectomy for cancer: a systematic review of the literature. Minerva Chir 2009;64:135-46.

17. Luketich JD, Pennathur A, Franchetti Y, et al. Minimally invasive esophagectomy: results of a prospective phase II multicenter trial-the eastern cooperative oncology group (E2202) study. Ann Surg 2015;261:702-7.

18. Gerhardus D. Robot-assited surgery: the future is here. J Healthc Manag 2003;48:242-51.

19. Bodner JC, Zitt M, Ott H, et al. Robotic-assisted thoracoscopic surgery (RATS) for benign and malignant esophageal tumors. Ann Thorac Surg 2005;80:1202-6.

20. Cerfolio RJ, Bryant AS, Hawn MT. Technical aspects and early results of robotic esophagectomy with chest anastomosis. J Thorac Cardiovasc Surg 2013;145:90-6.

21. Jin D, Yao L, Yu J, et al. Robotic-assisted minimally invasive esophagectomy versus the conventional minimally invasive one: A meta-analysis and systematic review. Int J Med Robot 2019;15:e1988.

22. Weksler B, Sharma P, Moudgill N, et al. Robot-assisted minimally invasive esophagectomy is equivalent to thoracoscopic minimally invasive esophagectomy. Dis Esophagus 2012;25:403-9.

23. Espinoza-Mercado F, Imai TA, Borgella JD, et al. Does the Approach Matter? Comparing Survival in Robotic, Minimally Invasive, and Open Esophagectomies. Ann Thorac Surg 2019;107:378-85.

Cite this article as: Young A, Alvarez Gallesio JM, Sewell DB, Carr R, Molena D. Outcomes of robotic esophagectomy. J Thorac Dis 2021;13(10):6163-6168. doi: 10.21037/jtd-2019-rts-07
24. Peyre CG, Hagen JA, DeMeester SR, et al. The number of lymph nodes removed predicts survival in esophageal cancer: an international study on the impact of extent of surgical resection. Ann Surg 2008;248:549-56.

25. Rizk N, Venkatraman E, Park B, et al. The prognostic importance of the number of involved lymph nodes in esophageal cancer: implications for revisions of the American Joint Committee on Cancer staging system. J Thorac Cardiovasc Surg 2006;132:1374-81.

26. National Comprehensive Cancer Network. Esophageal and esophagogastric junction cancers version 2. 2016. Available online: https://www.nccn.org. Accessed November 1, 2019.

27. Yerokun BA, Sun Z, Jeffrey Yang CF, et al. Minimally invasive vs open esophagectomy for esophageal cancer: a population based analysis. Ann Thor Surg 2016;102:403-9.

28. van der Horst S, de Maat MFG, van der Sluis PC, et al. Extended thoracic lymph node dissection in roboticassisted minimal invasive esophagectomy (RAMIE) for patients with superior mediastinal lymph node metastasis. Ann Cardiothorac Surg 2019;8:218-25.

29. Luketich JD, Pennathur A, Awais O, et al. Outcomes after minimally invasive esophagectomy: review of over 1000 patients. Ann Surg 2012;256:95-103.

30. Maas KW, Cuesta MA, Van Berge Henegouwen MI, et al. Quality of Life and Late Complications After Minimally Invasive Compared to Open Esophagectomy: Results of a Randomized Trial. World J Surg 2015;39:1986-93.

31. Parameswaran R, Titcomb DR, Blencowe NS, et al. Assessment and comparison of recovery after open and minimally invasive esophagectomy for cancer: an exploratory study in two centers. Ann Surg Oncol 2013;20:1970-7.

32. Sugawara K, Yoshimura S, Yagi K, et al. Long-term health-related quality of life following robot-assisted radical transmediastinal esophagectomy. Surg Endosc 2020;34:1602-11.

33. Yoshimura S, Mori K, Yamagata Y, et al. Quality of life after robot-assisted transmediastinal radical surgery for esophageal cancer. Surg Endosc 2018;32:2249-54. 